\section{Acidity (pH)}

\section{V. Galitskaya}

Sergeev Institute of Environmental Geoscience Russian

Academy of Sciences (IEG RAS), Moscow, Russia

\section{Definition}

Acidity $(\mathrm{pH})$ is numerically equal to the negative decimal logarithm of the activity of $\left(\mathrm{a}_{\mathrm{H}^{+}}\right)$or the concentration $\left[\mathrm{H}^{+}\right]$ of hydrogen ions (in gram ions per liter).

This concept was introduced in 1909 by the Danish chemist Sørensen. $\mathrm{pH}$ reflects the first letters of Latin words potentia hydrogeni - the power of hydrogen, or pondus hydrogenii - weight of hydrogen.

For low mineralized water, the difference between activity and concentration of hydrogen ions is not geochemically significant, but for high mineralized water the identification of activity and concentration is incorrect.

The introduction of $\mathrm{pH}$ as an indicator of acid-base properties of aqueous solutions was founded on the ability of water to dissociate into ions according to the scheme $\mathrm{H}_{2} \mathrm{O}=\mathrm{H}^{+}+\mathrm{OH}^{-}$. In connection with this reaction and using the concept of ionic product of water, $\mathrm{K}_{W}=\mathrm{a}_{\mathrm{H}+}+\mathrm{a}_{\mathrm{OH}-}$ (where

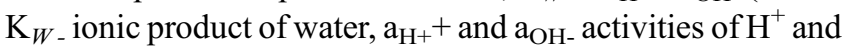
$\mathrm{OH}^{-}$respectively). $\mathrm{K}_{W}$ at $22{ }^{\circ} \mathrm{C}$ is equal $10^{-14}$. If the water does not contain other ions, the $\mathrm{H}^{+}$and $\mathrm{OH}^{-}$concentrations are equal according to the electroneutrality of ion activities and at $22{ }^{\circ} \mathrm{C}$ has the value of $10^{-7}$. In that condition, $\mathrm{pH}=\mathrm{pOH}=7$ (the neutral reaction medium). If $\mathrm{a}_{\mathrm{H}_{+}}>\mathrm{a}_{\mathrm{OH}}$ the solution is acidic $(\mathrm{pH}<7)$, if $\mathrm{a}_{\mathrm{H}^{+}}<\mathrm{a}_{\mathrm{OH}_{-}}$the solution is alkaline $(\mathrm{pH}>7)$.

The $\mathrm{pH}$ value is an important characteristic of all aqueous solutions and natural water bodies (rivers, lakes, seas, oceans). The $\mathrm{pH}$ value along with the reduction-oxidation (redox) potential determines the possible concentration in aqueous solutions of different chemical elements, their migration forms, and possible processes of changes of concentrations and properties of compounds. It also has effects on soils and ecosystems both terrestrial and aquatic (Kraynov et al. 2004).

\section{Cross-References}

- Acid Mine Drainage

$\checkmark$ Diagenesis

Dissolution

- Volcanic Environments

\section{References}

Kraynov SR, Rizhenko BN, Shvets VM (2004) Geochemistry of groundwater. Theoretical application and environmental aspects. Science, Moscow. (in Russian) 